\title{
BMJ Confidence in the future, health-related OPen behaviour and psychological distress: results from a web-based cross-sectional study of 101257 Finns
}

Kaisla Joutsenniemi, ${ }^{1}$ Tommi Härkänen, ${ }^{2}$ Maiju Pankakoski, ${ }^{1}$ Heimo Langinvainio, ${ }^{3}$ Antti S Mattila, ${ }^{4}$ Osmo Saarelma, ${ }^{5}$ Jouko Lönnqvist, ${ }^{1}$ Pekka Mustonen ${ }^{5}$
To cite: Joutsenniemi K, Härkänen T, Pankakoski M, et al. Confidence in the future, health-related behaviour and psychological distress: results from a webbased cross-sectional study of 101257 Finns. BMJ Open 2013;3:e002397.

doi:10.1136/bmjopen-2012002397

- Prepublication history and additional material for this paper is available online. To view these files please visit the journal online (http://dx.doi.org/10.1136/ bmjopen-2012-002397).

Received 23 November 2012 Revised 10 May 2013 Accepted 21 May 2013

This final article is available for use under the terms of the Creative Commons Attribution Non-Commercial 2.0 Licence; see http://bmjopen.bmj.com

For numbered affiliations see end of article.

Correspondence to Dr Kaisla Joutsenniemi; kaisla.joutsenniemi@ icloud.com

\section{ABSTRACT}

Objectives: To investigate the role of socioeconomic status and psychological stress to potential associations between confidence in the future and a wide range of health-related behaviours.

Design: Web-based cross-sectional study including an 'Electronic Health Check' at the Finnish HappinessFlourishing Study website linked to a TV programme on happiness and depression.

Setting: The Finnish population with access to the internet.

Participants: 101257 Finns aged 18 and above (21 365 men; 79892 women). Participants who were under the age of 18 and who did not provide information about their gender were excluded.

Primary outcome measures: As planned, we assessed smoking, weekly alcohol consumption and binge drinking, daily intake of fruits and vegetables and regular exercise.

Results: Compared with participants with low confidence in the future, those with high confidence were less likely to be daily smokers (men OR $0.58,95 \% \mathrm{Cl} 0.52$ to 0.65 ; women $0.57,95 \% \mathrm{Cl} 0.53$ to 0.61 ) and binge drinkers (men $0.57 ; 0.52$ to 0.63 ; women $0.54 ; 0.50$ to 0.57 ). Participants with high confidence in the future were more likely to exercise regularly (men $\mathrm{OR} 2.82,95 \% \mathrm{Cl}$ 2.55 to 3.13 ; women $2.57,95 \% \mathrm{Cl} 2.44$ to 2.71 ) and consume vegetables (men OR $2.48,95 \% \mathrm{Cl} 2.25$ to 2.74 ; women $2.13,95 \% \mathrm{Cl} 2.03$ to 2.24 ) and fruits (men $\mathrm{OR}$ $2.09,95 \% \mathrm{Cl} 1.86$ to 2.35 ; women $1.83,95 \% \mathrm{Cl} 1.74$ to 1.93) daily. Adjustment for current psychological distress and satisfaction for income attenuated the results.

Conclusions: Having confidence in the future is strongly associated with a healthy lifestyle, as assessed by a healthy diet, physical exercise and substance abuse. Health-related interventions may benefit from tailoring interventions according to the target population's level of confidence in the future as well as their level of psychological distress.

\section{INTRODUCTION}

Optimists benefit from expecting positive generalised outcomes ${ }^{1}$ and from explaining

\section{ARTICLE SUMMARY}

Article focus

- This study aims to investigate the role of socioeconomic status and psychological stress to potential associations between confidence in the future and a wide range of health-related behaviours.

- The web-based cross-sectional study including an 'Electronic Health Check' at the Finnish Happiness-Flourishing Study website was linked to a TV-programme on happiness and depression.

\section{Key messages}

- Our large, web-based study on Finnish adults confirms previous findings of an overall healthy lifestyle among participants with high confidence in the future.

- Participants with high confidence in the future were more likely to exercise regularly, and consume vegetables and fruits daily.

- Binge drinking, heavy drinking and daily smoking may be less common among participants with high confidence in the future.

Strengths and limitations of this study

- The sample size is considerably larger than in previous web-based studies, and we were able to assess a wide range of confounding factors as well as several health-related behaviours in one study.

- The TV programme with happiness-training for depressed participants may have attracted participants with corresponding needs to the website.

- No causal conclusions can be drawn from this cross-sectional study.

bad events with external, unstable and specific causes ${ }^{2}$ in terms of health. Previous longitudinal studies have shown the association between optimism and longevity ${ }^{3}{ }^{4}$ and optimism and mental ${ }^{5}$ and physical ${ }^{6}$ health. Less is known about the link between a specific dimension of optimism, that is, confidence in the future and health-related behaviour. 
For the sake of clarity, hereafter we use the term 'optimism' only when referring to the previous literature. Positive associations between optimism and proactive efforts in promoting health were reported in clinical study on patients in cardiac rehabilitation, as optimism predicted success in lowering levels of saturated fat and body fat and in increasing physical activity. ${ }^{7}$ A Finnish study recruited participants at increased risk for type 2 diabetes. The sample of men and women aged 50-65 participated in the Lifestyle Implementation Trial. Dispositional optimism and pessimism were unrelated to waist circumference change. ${ }^{8}$

Regarding community-based studies, a study on adults aged 40-60 years reported that optimists knew more about risk factors for heart-attacks than their less optimistic counterparts. ${ }^{9}$ In a study on elderly communityliving men, dispositional optimism associated with healthy lifestyle and dietary habits at 15-year follow-up independent of age, education, living arrangement and somatic morbidity. ${ }^{10}$ In an urban sample of men and women aged 65-80 years, optimism was associated with not smoking, moderate alcohol consumption and physical activity, independently of sociodemographic factors and clinical condition. ${ }^{11}$ Less is known about optimism and health-related behaviours in young adults. A study on young adults born in Northern Finland found optimists more likely to have a healthy diet and pessimists more likely to smoke or be high consumers of alcohol. No marked differences were found in the consumption of junk food. ${ }^{12}$

Psychological stress and socioeconomic status (SES) are well-known predictors of health-related behaviour. Psychological distress from marital problems, childcare $^{13}$ and work-related problems ${ }^{14}$ has been shown to be associated with increase in alcohol consumption and other health damaging behaviour. Higher prevalence of unhealthy behaviours in lower socioeconomic positions ${ }^{15}{ }^{16}$ is seen to be one of the mechanisms linking lower SES to worse health. ${ }^{17} 18$

Psychological distress and SES are also linked with optimism. Optimists' well-being is likely to be related to their characteristic, flexible coping methods with a variety of stressors ${ }^{19}$ and to accumulation of resources. ${ }^{20}$ Thus, SES and current psychological stress may partially explain the association between optimism and health-related behaviour.

A study with approximately 100000 women aged between 50 and 79 analysed whether optimism and pessimism, as measured by the revised Life Orientation Test (LOT-R), were prospectively associated with coronary heart disease (CHD) morbidity and with total mortality. Compared with pessimists, optimists had a lower rate of first episode CHD and mortality. The associations were independent of a number of sociodemographic variables, smoking, alcohol consumption and exercise, as well as depressive symptoms. ${ }^{4}$ Another recent study assessed the relationships between optimism and psychological distress in a sample of 284 depressed patients, who had undergone coronary bypass surgery. Compared with pessimists, optimists had lower rates of rehospitalisation. ${ }^{21}$

The Finnish Happiness-Flourishing Study (FHFS) is a national effort to promote positive mental health and positive health-related behaviour in the Finnish population. The aim of this study was to explore how one dimension of optimism, that is, high confidence in the future, is related to health-related behaviours and whether current socioeconomical status and psychological distress contribute to these relations in a large web-based sample of 101257 Finns aged 18 and above.

\section{DATA AND METHODS \\ Data}

The FHFS was a national collaboration with Duodecim Medical Publishing Ltd, the National Institute for Health and Welfare, Tarinatalo (a Finnish television production company) and Finland's national public service broadcasting company YLE. The collection of the webbased data was connected to a 'Reality TV' programme with happiness training for selected unhappy celebrities in 2009. Each of the eight episodes gained an audience of about 250000 viewers. The TV programme-guided viewers to a freely available happiness website, where 139462 Finns anonymously measured their own happiness on the Happiness-Flourishing Scale (HFS) and identified their important sources of happiness. The study website was also advertised on the television production company's own website. All Finnish-speaking individuals were eligible study participants irrespective of whether they had watched the TV programme or not. The website clearly stated that the collected data would be used for creating public summary reports on the happiness and factors connected to happiness. The time frame for filling out the questionnaires was 10 September 2009-17 August 2010. After filling the questionnaires, the participants instantly received data on how their overall happiness score (measured by a new HFS) compared with those of other Finns. The HFS was validated in a separate web-based random sample of Finns representing the population aged 17-79 $(\mathrm{N}=2035)$. The demographic characteristics of the validation sample are compared with the FHFS sample in online supplementary appendix 1 .

Some of the numerical variables were measured using an open text field in the internet questionnaire. These variables had impossible minimum and maximum values indicating typing errors. Restrictions were made on the maximum and minimum values of the following variables: income $(0-5000000)$, education years (0-participant's age), alcohol consumption (0-70 doses/week), cigarette consumption (0-100 cigarettes/day) and age $(7(18)-$ 110 years). In addition, we excluded participants who were under the age of 18 and who did not provide information about their gender. The final sample size after these restrictions was 101257 . No other exclusion or inclusion criteria were applied in this study (figure 1). 


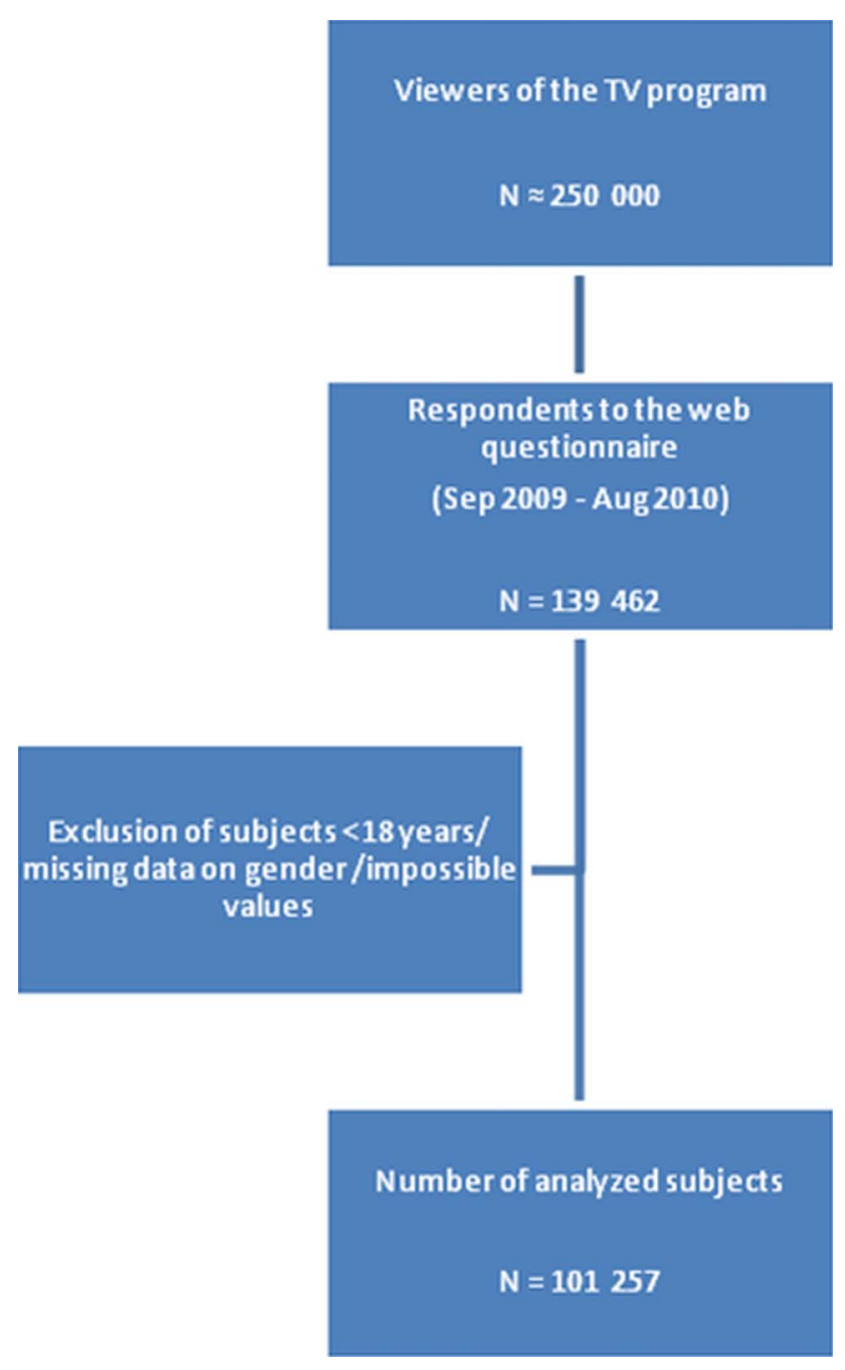

Figure 1 Flow chart.

\section{Variables}

Confidence in the future was assessed by the item 'I have complete confidence in the future', and participants were to choose a smiley face that best reflected their answer on a seven-point Likert scale 1 reflecting 'totally disagree' and 7 reflecting 'totally agree'. Answers 6-7 were classified as 'high confidence in the future' and answers 1-3 as 'low confidence in the future'. Eleven other happiness skills were similarly assessed: I devote a great deal of my time to those close to me; I am very grateful for everything that I have received and achieved; helping others comes naturally to me; I want to live in this moment; I enjoy outdoor activities, regular exercise and sports; I have firm life values that I aim to nurture; I see adversity as a challenge; I often become so absorbed in my work or tasks that I lose track of time; I find it easy to forgive; I draw strength from contemplation and meditation; I have clear goals in my life.

Smoking was assessed by the question "How many cigarettes, cigars or pipefuls do you smoke per day?" Smoking at least once a day was dichotomised as regular smoking. An open text field followed the question "How many units of alcohol do you drink per week?" At least 7 weekly doses for women and 14 for men were categorised as heavy alcohol consumption. Binge drinking was assessed with the question: "How often do you drink enough alcohol to feel yourself drunk?" with four response options. The answers reflecting drinking at least once a week were categorised as 'regular binge drinking'. The questions on food consumption were formulated "On average, how often do you eat fresh vegetables?" and "On average, how often do you eat fresh fruit or berries?" with response options: (1) less than once a week, (2) 1-2 times/week, (3) 3-5 times/week and (4) once a day or more. The answers reflecting daily consumption was dichotomised as 'regular consumption'. Leisure time physical activity was recorded by asking the following questions: "How much do you exercise and strain yourself physically in your leisure time?" (=the so-called Gothenburg scale) ${ }^{22}$ Answers reflecting at least $4 \mathrm{~h}$ of leisure exercise per week was dichotomised as 'regular physical activity'.

The level of education was captured with an openended question. "How many years in total have you attended school or studied full time?" and participants responded as full years. Education was included in the analyses as a continuous variable. Income was assessed with the question "What were the gross earnings for your household last year? (before tax is deducted)?" In the analyses the level of income was included as a continuous variable. Work-related distress was captured by asking "How often do you find yourself annoyed that you have to push yourself to the limit in order to cope with your present job or workload?" with five response options. Family-related distress was asked as follows: "Do you experience problems in your relationship with your spouse or partner?" with four response options and "Have your children caused you particular problems?" with six response options. Satisfaction with one's level of income was assessed with a seven-point Likert scale.

\section{Statistical analysis}

Descriptive statistics were reported for the large webbased sample. The missing data analyses were conducted using a logistic regression model. The missingness indicator of a variable, which had value 1 if the value was observed and 0 otherwise, was used as the outcome and the variables, which had fewer missing values, as independent variables. As the number of observations was large, the Bayesian information criterion, ${ }^{23}$ was applied in assessing important predictors of missing values.

Sequential logistic regression models were used to analyse the association between optimism and healthrelated behaviour. Results are presented in terms of adjusted OR and their 95\% CI. The analyses were performed separately for both genders. In the first model, the dichotomised health variable was explained by only optimism (and age). Education was added in the second model while the third model added income as a covariate. 
Finally, the fourth model added the psychological distress variables. Each analysis included only those participants who had data on all the variables included in the model. The R statistical software (V.2.15.0) was used in the analysis. The interaction between confidence in the future and gender was tested in all analyses, but results are only presented when the effects were significant.

\section{RESULTS}

\section{Description of study population}

The majority of the respondents in the FHFS data were women $(78.9 \%)$ and only $6.7 \%$ were aged over 64 (table 1). Low confidence in the future was reported by $14.5 \%$ of all participants, average confidence by $44.7 \%$ and high confidence by $40.8 \%$. Confidence in the future varied little by age and education. Regarding all measures of health-related behaviour, participants with high confidence in the future lead a healthier lifestyle and reported less psychological distress in both family and work contexts. The proportion of participants with high confidence was highest in the highest income quartile and they reported higher satisfaction with their income.

In separate analyses on income quartiles (figure 2), participants with high confidence in the future were more satisfied with their income irrespective of their level of income.

\section{Missing data}

Age and gender appeared to be the most important predictors for missing values, as very low and high age, as well as male gender predicted missing values in most variables (data not shown). In eating vegetables, the predictor was problems with children. In binge drinking, the predictors were problems with spouse or work-related distress all the time and eating vegetables less than once a week. In alcohol quantity, the predictors were problems with spouse all the time, eating vegetables at most twice a week and binge drinking less than once a month, in which case the alcohol quantity was likely to be close to zero. In income, the predictors were low physical activity, work-related distress all the time, small number of education years and lowalcohol consumption. In the number of cigarettes per day, the predictors were physical activity, problems with spouse not all the time, binge drinking at least once a week, small number of education years and consumption of alcohol. Variables related to smoking, alcohol consumpion, income or type of household contained relatively large amount of missing values (figure 3).

\section{Health-related behaviour and confidence in the future}

Compared with participants with low confidence in the future, those with high confidence in the future were less likely to be daily smokers (men OR $0.58,95 \%$ CI 0.52 to 0.65 ; women $0.57,95 \%$ CI 0.53 to 0.61 ; table 2 ). Participants with high confidence were also less likely to be regular binge drinkers (men OR $0.57,95 \%$ CI 0.52 to 0.63 ; women $0.54,95 \%$ CI 0.50 to 0.57 ) and less likely to consume alcohol in excess. Correspondingly, men and women with high confidence in the future were more likely to exercise regularly (men OR 2.82, 95\% CI 2.55 to 3.13 ; women $2.57,95 \%$ CI 2.44 to 2.71 ), and consume vegetables (men OR 2.48, 95\% CI 2.25 to 2.74; women 2.13 , 95\% CI 2.03 to 2.24) and fruits (men OR $2.09,95 \%$ CI 1.86 to 2.35 ; women 1.83 , $95 \%$ CI 1.74 to 1.93) daily. There was a significant gender interaction in daily consumption of fruits (Bonferroni $\mathrm{p}=0.00089$ ) and vegetables (Bonferroni $\mathrm{p}=0.00020$ ), in which the associations with high confidence in the future were stronger in men than in women.

Adjustment for education and income had little or no effect on the associations between high confidence in the future and health-related behaviours. Adjustment for current psychological distress at work or in family relationships, and particularly the adjustment for satisfaction with income attenuated the association between high confidence in the future and most health-related behaviours. Compared with participants with low confidence in the future, those with high confidence in the future remained less likely to be daily smokers (men OR 1.00 , $95 \%$ CI 0.86 to 1.17 ; women $0.87,95 \%$ CI 0.80 to 0.96 ), less likely to be regular binge drinkers (men OR 0.69, $95 \%$ CI 0.60 to 0.79 ; women $0.65,95 \%$ CI 0.59 to 0.71 ) and less likely to consume alcohol in excess (men OR $0.70,95 \%$ CI 0.60 to 0.82 ; women $0.73,95 \%$ CI 0.66 to $0.80)$. Participants with high confidence in the future remained more likely to exercise regularly (men OR $1.79,95 \%$ CI 1.55 to 2.06 ; women 2.57 , $95 \%$ CI 2.44 to 2.71 ), and consume vegetables (men OR $1.63,95 \%$ CI 1.43 to 1.87 ; women $1.56,95 \%$ CI 1.46 to 1.67 ) and fruits (men OR 1.55, 95\% CI 1.32 to 1.81 ; women 1.37, 95\% CI 1.28 to 1.47 ) daily. Among women, the association between high confidence in the future and heavy alcohol consumption was not affected by adjustment for psychological distress. Among men, the association between confidence in the future and smoking was rendered statistically insignificant after full adjustments, but other associations remained statistically significant in the full model.

\section{DISCUSSION}

\section{Principal findings}

Optimism, as assessed by the LOT, has previously been shown to associate with good health and a healthy lifestyle in studies focusing on middle-aged and elderly participants. To the best of our knowledge, data on a specific dimension of optimism, that is, confidence in the future, as well as information on the extent to which socioeconomic factors and psychological distress explain the association, are lacking. This web-based study found high confidence in the future to be strongly associated with several beneficial health-related behaviours and little psychological distress among both genders. Adjustment for current psychological distress at work and at home, as well as adjustment for satisfaction with 
Table 1 Background characteristics (\%) in the Finnish Happiness-Flourishing Study by level of confidence in the future (N=101 257)

\begin{tabular}{|c|c|c|c|c|c|c|c|c|c|c|c|}
\hline \multirow[b]{2}{*}{ Variable } & \multirow[b]{2}{*}{ Validt } & \multirow[b]{2}{*}{$\begin{array}{l}\text { Whole sample } \\
\mathrm{N}=101257\end{array}$} & \multirow[b]{2}{*}{ Validt } & \multicolumn{5}{|c|}{ Confidence in the future ${ }^{*}$} & \multirow[b]{2}{*}{$\chi^{2}$} & \multirow[b]{2}{*}{ df } & \multirow[b]{2}{*}{ p Value } \\
\hline & & & & $\begin{array}{l}\text { Low } 14.5 \% \\
\mathrm{~N}=12060\end{array}$ & Validt & $\begin{array}{l}\text { Moderate 44.7\% } \\
\mathrm{N}=37154\end{array}$ & Validt & $\begin{array}{l}\text { High } 40.8 \% \\
\mathrm{~N}=33936\end{array}$ & & & \\
\hline Gender (\%) & & & & & & & & & 92.9 & 2 & $<0.001$ \\
\hline Male & 100 & 21.1 & 100 & 22.1 & 100 & 18.4 & 100 & 20.4 & & & \\
\hline Female & & 78.9 & & 77.9 & & 81.6 & & 79.6 & & & \\
\hline Age (\%) & 100 & & 100 & & 100 & & 100 & & 757.9 & 8 & $<0.001$ \\
\hline $18-29$ & & 17.1 & & 22.4 & & 17.6 & & 14.9 & & & \\
\hline $30-44$ & & 30.4 & & 33.1 & & 31.9 & & 29.3 & & & \\
\hline $45-54$ & & 24.6 & & 24.5 & & 24.7 & & 25.4 & & & \\
\hline $55-64$ & & 21.2 & & 15.9 & & 19.8 & & 23.8 & & & \\
\hline$>65$ & & 6.7 & & 4.2 & & 5.9 & & 6.6 & & & \\
\hline Education years (\%) & 95.0 & & 97.2 & & 97.4 & & 97.9 & & 103.1 & 14 & $<0.001$ \\
\hline$<6$ & & 4.9 & & 5.5 & & 4.8 & & 4.6 & & & \\
\hline $6-7$ & & 2.7 & & 2.6 & & 2.6 & & 2.5 & & & \\
\hline $8-9$ & & 5.0 & & 5.0 & & 4.8 & & 5.0 & & & \\
\hline $10-12$ & & 18.9 & & 19.5 & & 18.5 & & 18.2 & & & \\
\hline $13-15$ & & 27.0 & & 27.0 & & 27.4 & & 26.8 & & & \\
\hline $16-18$ & & 27.9 & & 25.6 & & 28.0 & & 29.6 & & & \\
\hline $19-20$ & & 9.4 & & 9.8 & & 9.7 & & 9.3 & & & \\
\hline$>20$ & & 4.2 & & 5.0 & & 4.1 & & 4.1 & & & \\
\hline Income ${ }^{\ddagger}$ (€/year) (\%) & 89.9 & & 89.4 & & 90.0 & & 91.4 & & 1137.0 & 6 & $<0.001$ \\
\hline $0-17999$ & & 24.7 & & 32.2 & & 24.4 & & 22.6 & & & \\
\hline $18000-35999$ & & 24.5 & & 28.1 & & 26.1 & & 21.4 & & & \\
\hline $36000-59999$ & & 22.1 & & 20.2 & & 22.1 & & 22.3 & & & \\
\hline 60000 & & 28.8 & & 19.4 & & 27.4 & & 33.7 & & & \\
\hline Alcohol doses per week (\%) & 91.1 & & 91.0 & & 91.8 & & 92.6 & & 391.0 & 6 & $<0.001$ \\
\hline 0 & & 28.3 & & 30.8 & & 27.6 & & 28.6 & & & \\
\hline $1-5$ & & 44.4 & & 38.6 & & 45.4 & & 45.9 & & & \\
\hline $6-10$ & & 16.2 & & 15.5 & & 16.1 & & 16.2 & & & \\
\hline 11 & & 11.1 & & 15.1 & & 10.9 & & 9.3 & & & \\
\hline Binge drinking (\%) & 94.2 & & 97.1 & & 97.1 & & 96.9 & & 753.2 & 6 & $<0.001$ \\
\hline At least 2 times a week & & 5.1 & & 8.8 & & 4.8 & & 3.6 & & & \\
\hline At least once a week & & 12.4 & & 14.6 & & 12.7 & & 10.7 & & & \\
\hline At least once a month & & 23.5 & & 22.0 & & 24.6 & & 22.9 & & & \\
\hline Less than once a month & & 59.1 & & 54.6 & & 57.9 & & 62.9 & & & \\
\hline Daily smoking (\%) & 82.2 & & 85.3 & & 84.4 & & 85.2 & & 518.8 & 2 & $<0.001$ \\
\hline No & & 81.1 & & 74.0 & & 81.0 & & 84.2 & & & \\
\hline Yes & & 18.9 & & 26.0 & & 19.0 & & 15.8 & & & \\
\hline Fruits daily (\%) & 94.4 & & 97.5 & & 97.1 & & 97.4 & & 1182.2 & 2 & $<0.001$ \\
\hline No & & 57.9 & & 68.4 & & 59.9 & & 51.3 & & & \\
\hline Yes & & 42.1 & & 31.6 & & 40.1 & & 48.8 & & & \\
\hline
\end{tabular}




\begin{tabular}{|c|c|c|c|c|c|c|c|c|c|c|c|}
\hline \multirow[b]{2}{*}{ Variable } & \multirow[b]{2}{*}{ Valid† } & \multirow[b]{2}{*}{$\begin{array}{l}\text { Whole sample } \\
\text { N=101 } 257\end{array}$} & \multirow[b]{2}{*}{ Valid } & \multicolumn{5}{|c|}{ Confidence in the future ${ }^{\star}$} & \multirow[b]{2}{*}{$\chi^{2}$} & \multirow[b]{2}{*}{ df } & \multirow[b]{2}{*}{ p Value } \\
\hline & & & & $\begin{array}{l}\text { Low 14.5\% } \\
\mathrm{N}=12060\end{array}$ & Valid† & $\begin{array}{l}\text { Moderate } 44.7 \% \\
\mathrm{~N}=37154\end{array}$ & Valid† & $\begin{array}{l}\text { High } 40.8 \% \\
\mathrm{~N}=33936\end{array}$ & & & \\
\hline Vegetable daily (\%) & 95.6 & & 98.5 & & 98.4 & & 98.2 & & 1749.0 & 2 & $<0.001$ \\
\hline No & & 44.9 & & 58.2 & & 47.1 & & 37.1 & & & \\
\hline Yes & & 55.1 & & 41.8 & & 52.9 & & 62.9 & & & \\
\hline Physical exercise (\%) & 98.4 & & 99.1 & & 99.1 & & 99.2 & & 1963.8 & 6 & $<0.001$ \\
\hline Not much exercise & & 23.5 & & 36.9 & & 25.0 & & 17.7 & & & \\
\hline At least $4 \mathrm{~h}$ light exercise/week & & 46.5 & & 40.2 & & 46.5 & & 48.6 & & & \\
\hline At least $3 \mathrm{~h}$ heavy exercise/week & & 27.1 & & 20.7 & & 26.0 & & 30.1 & & & \\
\hline Training for sports competitions & & 2.9 & & 2.3 & & 2.4 & & 3.6 & & & \\
\hline Problems with children (\%) & 96.8 & & 97.7 & & 97.8 & & 97.9 & & 3275.6 & 10 & $<0.001$ \\
\hline I do not have children & & 33.8 & & 45.7 & & 35.3 & & 28.5 & & & \\
\hline Almost all the time & & 1.6 & & 3.8 & & 1.7 & & 0.7 & & & \\
\hline Quite often & & 5.1 & & 7.9 & & 5.8 & & 3.4 & & & \\
\hline Sometimes & & 14.2 & & 13.1 & & 15.3 & & 13.2 & & & \\
\hline Rarely & & 27.4 & & 18.9 & & 26.7 & & 30.8 & & & \\
\hline Never & & 18.0 & & 10.6 & & 15.2 & & 23.3 & & & \\
\hline Problems with spouse (\%) & 96.7 & & 97.1 & & 97.4 & & 97.7 & & 5130.3 & 6 & $<0.001$ \\
\hline I do not have a spouse & & 26.6 & & 38.3 & & 27.8 & & 22.0 & & & \\
\hline Almost all the time & & 7.4 & & 15.6 & & 8.2 & & 3.8 & & & \\
\hline Sometimes & & 43.9 & & 35.9 & & 46.6 & & 43.2 & & & \\
\hline Never & & 22.2 & & 10.2 & & 17.4 & & 31.1 & & & \\
\hline Work-related distress (\%) & 96.2 & & 98.9 & & 99.0 & & 99.0 & & 8798.4 & 8 & $<0.001$ \\
\hline No work or studies & & 13.9 & & 19.0 & & 13.0 & & 12.6 & & & \\
\hline Almost all the time & & 6.9 & & 19.5 & & 7.1 & & 2.6 & & & \\
\hline Quite often & & 16.3 & & 25.1 & & 19.5 & & 9.8 & & & \\
\hline Sometimes & & 38.6 & & 26.6 & & 40.5 & & 40.5 & & & \\
\hline Rarely or never & & 24.3 & & 9.8 & & 19.9 & & 34.6 & & & \\
\hline $\begin{array}{l}\text { Satisfaction with economical } \\
\text { situation }(1-7)(\%)\end{array}$ & 94.2 & & 97.2 & & 97.1 & & 96.6 & & 13112.2 & 4 & $<0.001$ \\
\hline 1-3 low & & 21.2 & & 51.7 & & 22.7 & & 9.0 & & & \\
\hline 4-5 average & & 44.9 & & 35.1 & & 51.9 & & 40.6 & & & \\
\hline $6-7$ high & & 34.0 & & 13.2 & & 25.4 & & 50.4 & & & \\
\hline
\end{tabular}




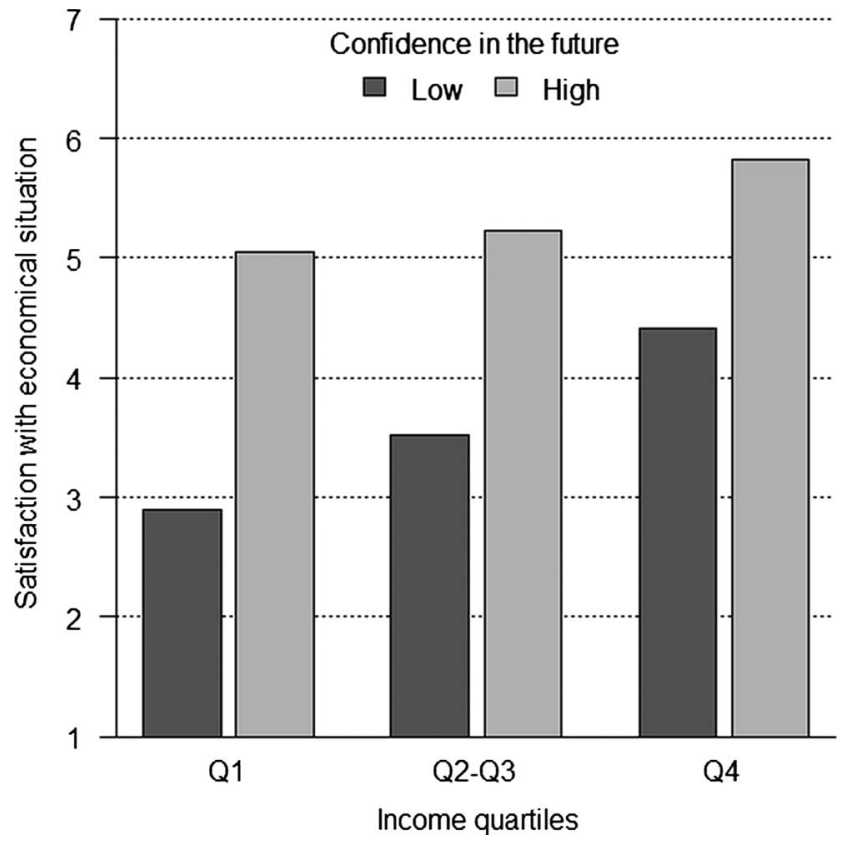

Figure 2 Confidence in the future, satisfaction with economical situation and income.

income, attenuated the associations. Nevertheless, disregarding smoking among men, the findings held in multivariable adjusted models in both genders.

\section{Strengths and weaknesses}

There are several strengths in this study. First, the sample size is considerably larger than in previous studies on optimism, which enables better detection of associations between confidence in the future, health behaviour and related mechanisms. Furthermore, we

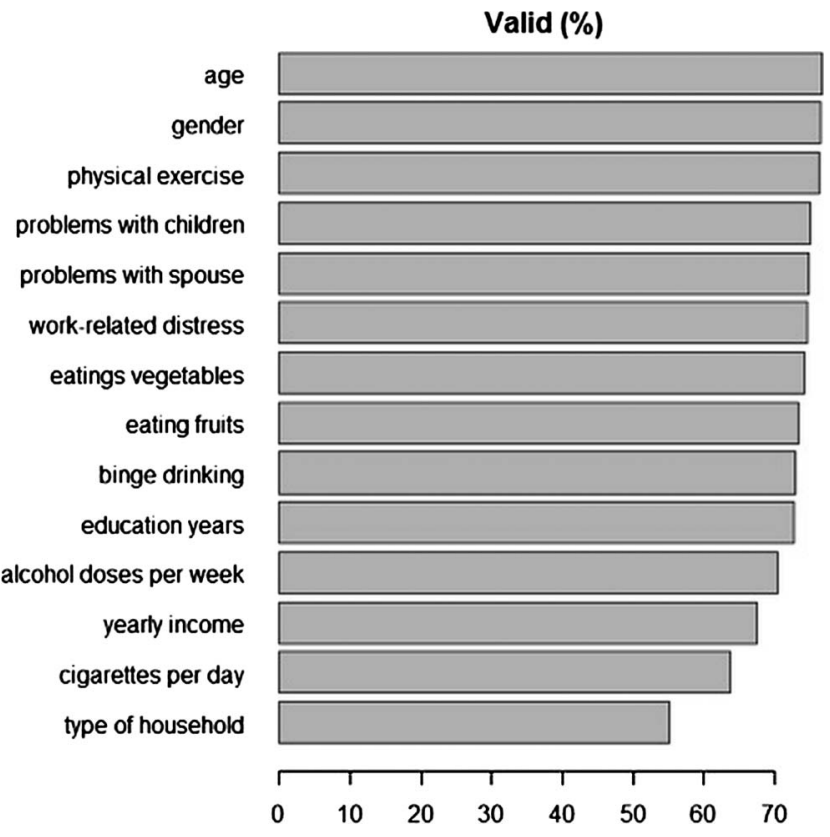

Figure 3 Missing data in the Finnish Happiness-Flourishing Study. also captured younger age-groups than previous studies. Second, we were able to assess a wide range of confounding factors, although the possibility of residual confounding cannot be fully excluded. Third, the sociodemographic distribution of the FHFP, as reflected by level of education, was roughly comparable to another Finnish survey conducted in 2009. ${ }^{24}$ A random sample $(n=5000)$ of Finnish adults aged between 15 and 64 was derived from the Population Register for an annual survey, which was answered by $59 \%$ of the sample. The proportion of participants with basic education was about $15 \%$ compared with $13 \%$ in the FHFS, whereas higher education (ie, over 12 years) was reported by $56 \%$ and $69 \%$, correspondingly. ${ }^{24}$ Finally, we were able to assess several health-related behaviours in one study.

However, there are also limitations in this study that must be considered. First, due to self-selection, the generalisability of these results is limited. The TV programme with happiness-training for depressed participants may have attracted participants with corresponding needs to the website. However, the average score for confidence in the future in the national sample of 2035 Finns was 5.08 compared with 5.00 in the web-based sample, indicating a rather small potential bias. Accordingly, a previous study on 912 online happiness seeking adults found that the participants reported depressive symptoms above the mean of the general population and life satisfaction below the average. ${ }^{25}$ Furthermore, we had no information on whether the participants had actually watched the happiness-related TV programme or not. However, watching the TV programme was unlikely to bias our results on the connection between confidence in the future and health-related behaviours. Also, the happiness-related website appeared to attract more women than men. Second, no causal conclusions can be drawn from this cross-sectional study. Third, missing values in the analysis variables were often related to low education, problems with spouse, work-related distress, number of adults in the household or alcohol use, although the directions of the associations varied from variable to variable. A possible future development could be the multiple imputation of the missing data in order to assess the effects of, and to remove the possible bias caused by the missing data. Fourth, this study includes only one item that measures optimism, that is, confidence in the future. Thus, these results should not be interpreted to reflect all dimensions of optimism. Fifth, our self-reported measure on binge drinking may underestimate the level of true binge drinking; due to tolerance, individuals may not feel drunk despite consuming heavy amounts of alcohol. Sixth, this study used several non-validated single item questions on background variables such as psychological distress. This decision was made in order to ensure user-friendliness in a large, web-based study. Seventh, we had relatively large proportions of missing data for several variables. However, this is a common problem shared by most web-based studies. Regarding 
Table 2 High confidence in the future ${ }^{\star}$ and health-related behaviours with various adjustments

Men (N=7 688-9 526)

\begin{tabular}{|c|c|c|c|c|c|c|c|c|c|c|c|c|c|}
\hline \multirow[b]{2}{*}{ Model } & \multirow[b]{2}{*}{ adjustment } & \multicolumn{2}{|c|}{ Daily smoking } & \multicolumn{2}{|c|}{$\begin{array}{l}\text { Heavy alcohol } \\
\text { consumption } \\
\text { ( } \geq 14 \text { doses/week) }\end{array}$} & \multicolumn{2}{|c|}{$\begin{array}{l}\text { Regular binge } \\
\text { drinking ( } \geq \text { once a } \\
\text { week) }\end{array}$} & \multicolumn{2}{|c|}{$\begin{array}{l}\text { Daily fruit } \\
\text { consumption }\end{array}$} & \multicolumn{2}{|c|}{$\begin{array}{l}\text { Daily vegetable } \\
\text { consumption }\end{array}$} & \multicolumn{2}{|c|}{$\begin{array}{l}\text { Regular physical } \\
\text { activity }\end{array}$} \\
\hline & & $\overline{\text { OR }}$ & $95 \% \mathrm{Cl}$ & $\overline{\text { OR }}$ & $95 \% \mathrm{Cl}$ & $\overline{\text { OR }}$ & $95 \% \mathrm{Cl}$ & $\overline{\text { OR }}$ & $95 \% \mathrm{Cl}$ & $\overline{\text { OR }}$ & $95 \% \mathrm{Cl}$ & $\overline{\text { OR }}$ & $95 \% \mathrm{Cl}$ \\
\hline 1 & Age only & 0.58 & 0.52 to 0.65 & 0.52 & 0.46 to 0.58 & 0.57 & 0.52 to 0.63 & 2.09 & 1.86 to 2.35 & 2.48 & 2.25 to 2.74 & 2.82 & 2.55 to 3.13 \\
\hline 2 & Education & 0.58 & 0.52 to 0.65 & 0.51 & 0.46 to 0.58 & 0.57 & 0.52 to 0.63 & 2.08 & 1.85 to 2.34 & 2.48 & 2.25 to 2.74 & 2.82 & 2.54 to 3.13 \\
\hline 3 & Income & 0.61 & 0.55 to 0.69 & 0.50 & 0.44 to 0.56 & 0.56 & 0.50 to 0.62 & 2.09 & 1.85 to 2.37 & 2.30 & 2.07 to 2.55 & 2.78 & 2.50 to 3.10 \\
\hline 4 & Psychological distress $†$ & 0.72 & 0.63 to 0.83 & 0.59 & 0.51 to 0.67 & 0.65 & 0.57 to 0.73 & 1.94 & 1.68 to 2.23 & 2.04 & 1.81 to 2.30 & 2.30 & 2.02 to 2.62 \\
\hline 5 & Satisfaction with income & 1.00 & 0.86 to 1.17 & 0.70 & 0.60 to 0.82 & 0.69 & 0.60 to 0.79 & 1.55 & 1.32 to 1.81 & 1.63 & 1.43 to 1.87 & 1.79 & 1.55 to 2.06 \\
\hline \multicolumn{14}{|c|}{ Women ( $\mathrm{N}=26$ 035-36 079) } \\
\hline \multirow[b]{2}{*}{ Model } & \multirow[b]{2}{*}{ adjustment } & \multicolumn{2}{|c|}{ Daily smoking } & \multicolumn{2}{|c|}{$\begin{array}{l}\text { Heavy alcohol } \\
\text { consumption } \\
\text { ( } \geq 7 \text { doses/week) }\end{array}$} & \multicolumn{2}{|c|}{$\begin{array}{l}\text { Regular binge } \\
\text { drinking ( } \geq \text { once a } \\
\text { week) }\end{array}$} & \multicolumn{2}{|c|}{$\begin{array}{l}\text { Daily fruit } \\
\text { consumption }\end{array}$} & \multicolumn{2}{|c|}{$\begin{array}{l}\text { Daily vegetable } \\
\text { consumption }\end{array}$} & \multicolumn{2}{|c|}{$\begin{array}{l}\text { Regular physical } \\
\text { activity }\end{array}$} \\
\hline & & $\overline{\text { OR }}$ & $95 \% \mathrm{Cl}$ & $\overline{\mathrm{OR}}$ & $95 \% \mathrm{Cl}$ & $\overline{\text { OR }}$ & $95 \% \mathrm{Cl}$ & $\overline{\text { OR }}$ & $95 \% \mathrm{Cl}$ & $\overline{\text { OR }}$ & $95 \% \mathrm{Cl}$ & $\overline{\text { OR }}$ & $95 \% \mathrm{Cl}$ \\
\hline$\overline{1}$ & Age only & 0.57 & 0.53 to 0.61 & 0.67 & 0.62 to 0.71 & 0.54 & 0.50 to 0.57 & 1.83 & 1.74 to 1.93 & 2.13 & 2.03 to 2.24 & 2.57 & 2.44 to 2.71 \\
\hline 2 & Education & 0.57 & 0.54 to 0.61 & 0.66 & 0.62 to 0.71 & 0.54 & 0.50 to 0.57 & 1.84 & 1.74 to 1.93 & 2.13 & 2.03 to 2.24 & 2.55 & 2.42 to 2.69 \\
\hline 3 & Income & 0.61 & 0.57 to 0.66 & 0.63 & 0.59 to 0.68 & 0.53 & 0.49 to 0.56 & 1.83 & 1.73 to 1.93 & 2.07 & 1.96 to 2.18 & 2.56 & 2.41 to 2.71 \\
\hline 4 & Psychological distress $†$ & 0.69 & 0.64 to 0.75 & 0.64 & 0.59 to 0.69 & 0.57 & 0.52 to 0.62 & 1.64 & 1.54 to 1.75 & 1.83 & 1.73 to 1.95 & 2.22 & 2.07 to 2.37 \\
\hline 5 & Satisfaction with income & 0.87 & 0.80 to 0.96 & 0.73 & 0.66 to 0.80 & 0.65 & 0.59 to 0.71 & 1.37 & 1.28 to 1.47 & 1.56 & 1.46 to 1.67 & 1.84 & 1.71 to 1.99 \\
\hline
\end{tabular}


web-based interventions, it has been suggested that individuals may approach them differently than more traditional methods, and that 'dropouts' may in fact be individuals who received adequate help with a lower 'dose' of treatment. With caution, this may also apply to our cross-sectional study, as our study participants may have selected to fill out the questionnaires they found most interesting or useful regarding the automated feedback they received on their happiness score. ${ }^{26}$

\section{Strengths and weaknesses in relation to other studies}

In line with our results, a previous Finnish study ${ }^{12}$ on 31-year-old men and women $(\mathrm{n}=8690)$ found optimism, as measured by the six-item LOT-R, to associate with high consumption of fruits and vegetables, whereas pessimism associated with tendency to smoke and to consume alcohol excessively. The data included a vast range of sociodemographic factors, but no information on psychological distress. Our study adds to these findings by showing strong negative associations between confidence in the future and binge drinking, as well as a positive association between high confidence and regular exercise.

In a relatively small $(\mathrm{n}=128)$ sample of men and women aged 65-80 years recruited from general practices in urban Great Britain, optimism was associated with high physical activity, not smoking and moderate alcohol consumption, independently of education, area deprivation, clinical condition and medication. ${ }^{11}$ With optimism assessed by the (LOT-R), their results support our findings on the positive association between optimism and beneficial health-related behaviours. Data on diet and psychological stress are unavailable for comparison.

In a prospective Dutch study of 773 elderly community-living men, dispositional optimism was associated with regular physical activity, being a non-smoker, higher alcohol consumption and higher consumption of vegetables and fruits at 15-year follow-up independent of sociodemographic factors and somatic morbidity. ${ }^{10}$ Dispositional optimism was assessed by four items. In a cross-sectional setting, we show similar results among both genders and in a wider age group.

In short, previous studies show an exhaustive range of dietary variables and rigorously assessed sociodemographic background characteristics. Our study adds to the literature by examining a range of health-related behaviours, and by assessing the role of psychological distress. With caution, and bearing in mind that we only measured one dimension of optimism with one item, our results for high and low confidence in the future appear to be in the exact directions and magnitude expected for optimism and pessimism, respectively.

Turning to previous findings on SES, a longitudinal study on 694 Finns found parental SES in childhood to predict higher dispositional optimism (overall LOT score) irrespective of current SES. ${ }^{27}$ Another longitudinal study on 61 former law students aged $30-47$ at follow-up found high baseline optimism (LOT) to predict higher income after controlling for hours worked. On the other hand, higher income did not increase optimism at follow-up. ${ }^{20}$ Although we can draw no conclusions about causal directions, our data add to previous literature by showing that participants with high confidence in the future report higher satisfaction with their income irrespective of their income level.

As previously discussed, ${ }^{28}$ it might seem paradoxical that people who expect good things to happen take the initiative and actively promote the good things. According to a recent meta-analysis, optimists' characteristic coping style includes techniques for managing both stressful problems and stress-induced emotions. ${ }^{19}$ Optimists were also flexible regarding the source and type of stress they were faced with. This flexibility likely accounts for highly confident participant's resilience to stressful events ${ }^{28}$ such as family-related and work-related stressors in our data.

\section{CONCLUSIONS}

This study produced further evidence, as high confidence in the future appeared to associate with a range of beneficial health-related behaviours and lowpsychological distress in different areas of life. Although no causal conclusions can be drawn from this study, participants with high confidence in the future appeared to make the effort to promote a healthy lifestyle irrespective of educational level or financial situation. Longitudinal studies in different populations are needed to disentangle the cause and effect chain between different dimensions of optimism and health-related behaviours. Future health-related interventions may benefit from tailoring each intervention according to the target population's level of confidence in the future as well as their level of psychological distress. Furthermore, more research is needed to increase the current understanding of changes in confidence in the future with alternating loads and quality of psychological distress.

\section{Author affiliations}

${ }^{1}$ National Institute for Health and Welfare, Department of Mental Health and Substance Abuse Services, Helsinki, Finland

${ }^{2}$ National Institute for Health and Welfare, Department of Health, Functional Capacity and Welfare, Helsinki, Finland

${ }^{3}$ CompetenceAudit Center, Helsinki, Finland

${ }^{4}$ Antifon, Helsinki, Finland

${ }^{5}$ Duodecim Medical Publications Ltd, Helsinki, Finland

Acknowledgements We warmly thank the staff of Duodecim Medical Publications Ltd and experts at Finnish Medical Society Duodecim for their continuous support in the Finnish Happiness Project.

Contributors OS, HL, ASM, TH, JL and PM designed the study. KJ managed the literature searches and wrote the first draft of the manuscript. MP undertook the statistical analysis under the supervision of TH and KJ. MP and $\mathrm{TH}$ wrote the chapters on statistical methods. HL and ASM provided their expertise in research of positive psychology. All authors contributed to and have approved the final manuscript.

Funding The study was a collaboration between The National Institute for Health and Welfare (THL) and Duodecim Medical Publications. The funding was provided by Tekes-the Finnish Funding Agency for Technology and Innovation through SALWE-centre. The study was partly supported by the 
SalWe Research Program for IM0 (Tekes-the Finnish Funding Agency for Technology and Innovation grant 648/10). SalWe Ltd has been established in May 2009 by Finnish forerunner companies and research organisations to develop expertise and international business activities of the health and well-being cluster in Finland. The funders had no role in the analysis and interpretation of the data, in the writing of the article or in the decision to submit the article for publication. OS is the Chief Editor and PM is the CEO at Duodecim Medical Publications, which is fully owned by the Finnish Medical Society Duodecim. OS and PM were involved with designing the gathering of the data but the data analyses were carried out by the researchers at THL. HL and $A M$ are independent experts with no funding for this study.

Competing interests $\mathrm{KJ}, \mathrm{MP}, \mathrm{TH}, \mathrm{HL}, \mathrm{AM}, \mathrm{OS}$, JL and PM have support from the National Institute for Health and Welfare or Duodecim Medical Publications Ltd for the submitted work.

Provenance and peer review Not commissioned; externally peer reviewed.

Data sharing statement No additional data are available.

\section{REFERENCES}

1. Scheier M, Carver C. Optimism, coping, and health: assessment and implication of generalized outcome expectancies. Health Psychol 1985;4:219-47.

2. Buchanan G, Seligman M. Explanatory style. Hillsdale, NJ: Erlbaum, 1995.

3. Maruta $\mathrm{T}$, Colligan $\mathrm{R}$, Malinchoc $\mathrm{M}$, et al. Optimists vs pessimists: survival rate among medical patients over a 30 -year period. Mayo Clin Proc 2000;75:140-3.

4. Tindle $\mathrm{H}$, Chang $\mathrm{Y}$, Kuller L, et al. Optimism, cynical hostility, and incident coronary heart disease and mortality in the Women's Health Initiative. Circulation 2009;120:656-62.

5. Mosing H, Zietsch B, Shekar S, et al. Genetic and environmental influences on optimism and its relationship to mental and self-rated health: a study of Aging Twins. Behav Genet 2009;39:597-604.

6. Rasmussen H, Scheier M, Greenhouse J. Optimism and physical health: a meta-analytic review. Ann Behav Med 2009;37:239-56.

7. Shepperd J, Maroto J, Pbert L. Dispositional optimism as a predictor of health changes among cardiac patients. J Res Pers 1996;30:517-34.

8. Hankonen N, Vollmann M, Renner B, et al. What is setting the stage for abdominal obesity reduction? A comparison between personality and health-related social cognitions. J Behav Med 2010;33:415-22.

9. Radcliffe N, Klein W. Dispositional, unrealistic, and comparative optimism: differential relations with the knowledge and processing of risk information and beliefs about personal risk. Pers Soc Psychol $B$ 2002;28:836-46.
10. Giltay E, Geleijnse J, Zitman F, et al. Lifestyle and dietary correlates of dispositional optimism in men: the Zutphen Elderly Study. $J$ Affect Disord 2006;91:45-52.

11. Steptoe A, Wright C, Kunz-Ebrecht S, et al. Dispositional optimism and health behaviour in community-dwelling older people: associations with healthy ageing. Br J Health Psychol 2006;11:71-84.

12. Kelloniemi H, Ek E, Laitinen J. Optimism, dietary habits, body mass index and smoking among young Finnish adults. Appetite 2005;45:169-76.

13. Leonard K, Eiden R. Marital and family processes in the context of alcohol use and alcohol disorders. Annu Rev Clin Psychol 2007;3:285-310.

14. Siegrist J, Rödel A. Work stress and health risk behavior. Scand $J$ Work Environ Health 2006;32:473-81.

15. Martikainen P, Brunner E, Marmot M. Socioeconomic differences in dietary patterns among middleaged men and women. Soc Sci Med 2003;56:1397-410.

16. Lakka T, Kauhanen J, Salonen J. Conditioning leisure time physical activity and cardiorespiratory fitness in sociodemographic groups of middle-aged men in eastern Finland. Int J Epidemiol 1996;25: 86-93.

17. Townsend P, Davidson N. Inequalities in health: the black report. Harmondsworth, England: Penguin Books, 1982.

18. Macintyre S. The black report and beyond. Soc Sci Med 1997;44:723-45.

19. Solberg Nes L, Segerstrom S. Dispositional optimism and coping: a meta-analytic review. Pers Soc Psychol Rev 2006;10:235-51.

20. Segerstrom S. Optimism and resources: effects on each other and on health over 10 years. J Res Pers 2007:41:772-86.

21. Tindle $\mathrm{H}$, Herbeck Belnap B, Houck $\mathrm{P}$, et al. Optimism, response to treatment of depression, and rehospitalization after coronary artery bypass graft surgery. Psychosom Med 2012;74:200-7.

22. Wilhelmsen L, Tibblin G, Werko L. A primary preventive study of Gothenburg, Sweden. Prev Med 1972;1:153-60.

23. Schwarz G. Estimating the dimension of a model. Ann Stat 1978;6:461-4

24. Helakorpi S. Health behaviour and health among the Finnish adult population, Spring 2009. http://urn.fi/URN:NBN:fi-fe201205085392 [in Finnish, abstract in English]; 2010.

25. Parks A, Della Porta M, Pierce R, et al. Pursuing happiness in everyday life: the characteristics and behaviours of online happiness seekers. Emotion 2012;12:1222-34.

26. Christensen $\mathrm{H}$, Mackinnon A. The law of attrition revisited. $J$ Med Internet Res 2006;8:e20.

27. Heinonen K, Räikkönen $\mathrm{K}$, Matthews $\mathrm{K}$, et al. Socioeconomic status in childhood and adulthood: associations with dispositional optimism and pessimism over a 21-year follow-up. $J$ Pers 2006;74:1111-26.

28. Carver V, Connor-Smith J. Personality and coping. Annu Rev Psychol 2010;61:679-704. 